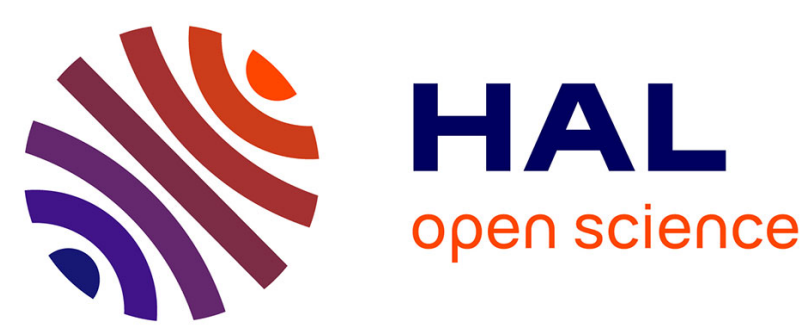

\title{
Systematic lidar measurements of the stratospheric ozone vertical distribution
}

Sophie Godin, Gérard Mégie, Jacques Pelon

\section{To cite this version:}

Sophie Godin, Gérard Mégie, Jacques Pelon. Systematic lidar measurements of the stratospheric ozone vertical distribution. Geophysical Research Letters, 1989, 16 (6), pp.547-550. 10.1029/GL016i006p00547 . insu-01263583

\section{HAL Id: insu-01263583 \\ https://hal-insu.archives-ouvertes.fr/insu-01263583}

Submitted on 12 Mar 2021

HAL is a multi-disciplinary open access archive for the deposit and dissemination of scientific research documents, whether they are published or not. The documents may come from teaching and research institutions in France or abroad, or from public or private research centers.
L'archive ouverte pluridisciplinaire HAL, est destinée au dépôt et à la diffusion de documents scientifiques de niveau recherche, publiés ou non, émanant des établissements d'enseignement et de recherche français ou étrangers, des laboratoires publics ou privés. 


\title{
SYSTEMATIC LIDAR MEASUREMENTS OF THE STRATOSPHERIC OZONE VERTICAL DISTRIBUTION
}

\author{
S. Godin, G. Mégle, J. Pelon
}

Service d'Aéronomie CNRS, Université Pierre et Marie Curie, Paris

Abstract. Lidar measurements of the ozone vertical distribution have been performed on a routine basis at the Observatoire de Haute-Provence, starting in October 1986. They provide a unique data base which is used to derive the observed seasonal behaviour of ozone in various altitude ranges from 25 to $45 \mathrm{~km}$ with a height resolution much higher than previous operational systems. Comparison with Umkehr measurements performed at the same location show a rather good agreement in layers 5 and 6 with unexpected differences appearing in the uppermost layers.

\section{Introduction}

Early detection of changes in the stratospheric chemical composition and structure related to human activities is a major issue for the protection of the ozone layer. A recent study (NASA, 1988) shows that satellite observations alone, despite their global coverage of the stratospheric ozone field, are not sufficient to provide an accurate determination of trends, mainly because of drifts in instrument calibration. It is thus fully recognized that complementary ground-based measurements are a required component of any global ozone observation system. Such measurements should be conducted routinely from several sites at different latitudes to constitute an effective Network for the Detection of Stratospheric Changes (NDSC-NASA, 1986). As part of the various passive (UV-visible, infrared, microwave spectrometers) and active systems to be implemented, lidars are recognized as being the required instrument to provide the most accurate measurements of the ozone vertical distribution from the ground up to the $45-50 \mathrm{~km}$ level.

Since the early development of the ozone lidar at the Observatoire de Haute Provence (OHP - Mégie et al., 1977 ; Pelon and Mégie, 1982a) several improvements have been brought to the system which have resulted in successive increases in the maximum attainable height of the measurements (Pelon and Mégie, 1982b; Mégie et al., 1985). As a last step, a new excimer laser source has been implemented in 1986, to improve the reliability of the system allowing routine operation starting in October 1986 (Godin et al., 1986). Such a two years measurement period is obviously too short to provide any indication on potential trends. The data reported here will thus be analysed in terms of seasonal variations and compared to measurements performed at the same location by

Copyright 1989 by the American Geophysical Union.

Paper number $89 \mathrm{GL} 00261$. $0094-8276 / 89 / 89 \mathrm{GL}-00261 \$ 03.00$ the Umkehr technique using a Dobson spectrophotometer (Marché et al., 1983). A brief description of the system and of the data processing methods will be given in sections 2 and 3. Data analysis and results of comparison will be presented in section 4.

\section{Operational lidar system}

The lidar measurements of the ozone vertical distribution are based on the Differential Absorption Laser (DIAL) technique (Schotland, 1964 ; Mégie and Menzies, 1980) which requires the simultaneous emission of two laser wavelengths. The ozone absorbed wavelength (on line) is provided by a Xenon Chloride excimer laser emitting at $308 \mathrm{~nm}$ (Lambda Physics MG 201). An unstable resonator cavity arrangement is used to reduce the laser divergence down to $0.5 \mathrm{mrad}$. The reference wavelength is obtained using the 3rd harmonic (355 nm) of a Nd:Yag laser, the output energy of which is adapted to provide a return signal equivalent to the on-1ine signal at $40 \mathrm{~km}$ altitude. This is done to preserve the same dynamical range for the signals at the two wavelengths in the whole altitude domain. Due to saturation problems in the photodetectors, an additional acquisition is also performed at reduced emitted energy to derive lower altitude profiles in the $15-35 \mathrm{~km}$ altitude range. Further details of the experimental procedure have been given in a previous publication (Godin et al., 1986). In today operation, the nighttime measurement of the ozone vertical distribution in the 15-45 $\mathrm{km}$ range requires an integration time of 3 hours.

\section{Data processing}

Two types of errors can directly influence the DIAL measurement of the ozone vertical distribution. The statistical error related to the signal to noise ratio defines the limits of the precision of the measurement. Systematic errors due to interferences of molecular and aerosol scattering and extinction, and to temperature dependence of the ozone cross-sections will affect the accuracy of the retrieved ozone profile. Such uncertainties have already been quantified in previous publications (Mégie et al, 1985 ; Godin et al., 1986). The possible bias which can be induced by the data processing has also been carefully analysed by simulations using a direct-inverse modeling scheme and a Monte-Carlo method (Godin, 1987). For the present analysis this study has led to the use of a combination of linear digital filters which corresponds to a compromise at high altitudes between the systematic bias on the retrleved ozone values and the magnitude of the statistical error in order to keep the 
overall uncertainty of the measurement lower than 58 at $40 \mathrm{~km}$ for a vertical resolution of $3 \mathrm{~km}$.

\section{Data analysis}

The ozone lidar system at the observatoire de Haute-Provence has been operated on a research mode in 1984-1985 and on an operational mode starting in October 1986. On the whole period, more than sixty ozone profiles have been obtained in the altitude range from 25 to $45 \mathrm{~km}$, allowing thus a study of the absolute value and seasonal variations of the ozone content at various altitudes. Concerning the absolute values of the ozone number density, the data show usually a good agreement within 158 with the U.S. Standard Atmosphere 1976 values which corroborates the already observed discrepancy with calculated ozone vertical distributions above $35 \mathrm{~km}$. (WMO, 1985).

Furthermore, taking advantage of the unique capacity provided by the OHP Geophysical Station to obtain simultaneous measurements of ozone distribution by lidar and Umkehr technique, comparison between these two techniques can be performed on a statistically signiflcant basis. Such comparisons require the conversion of the lidar data (number density vs. height) in units compatible with Umkehr retrieved values (partial pressure in various pressure intervals). Lidar data have first been averaged over the altitude range of the Umkehr layers using pressure-altitude conversion as given by the CIRA 1986 model which includes seasonal and latitudinal variations. The lidar number density ozone values have then been converted to partial pressure using temperature profiles taken again from the CIRA 1986 atmospheric model. Both data sets have first been compared in terms of the seasonal variations. To that end, we have calculated for each measurement the difference with the total mean for the years 1985-1987. Those differences, as obtained by lidar for the Umkehr layers $5(23.5-28 \mathrm{~km}), 6(28-33 \mathrm{~km})$ and $7(33-38.5 \mathrm{~km})$, are represented in per cents as a function of the day of the year and for the three consecutive years on the figures $1 a, 1 b$, 1c. Accurate measurements in layer 8 are yet too few to make a significant stastistical analysis. Due to bad weather conditions in 1986 and 1987 at the end of spring in the south of France, few profiles have been obtained during this period, and none in june. Besides, as mentionned earlier, these data correspond to different experimental set-ups and different operational modes throughout the three years involved in this analysis. This explains the discrepancies in the number of profiles used to determine the seasonal variation in the various Umkehr layers. On these figures, the bold lines represent the monthly average and the thin lines the related standard deviation. The amplitude of the seasonal variation is defined in the following analysis as the difference between the lowest and highest monthly averages. In the layer 5 , (figure $1 \mathrm{a}$ ), the seasonal variation of ozone is less than 5 if one excepts the January values. This latter corresponds in fact to only three measurements taken during consecutive days in January 1987 at a time of the year when the
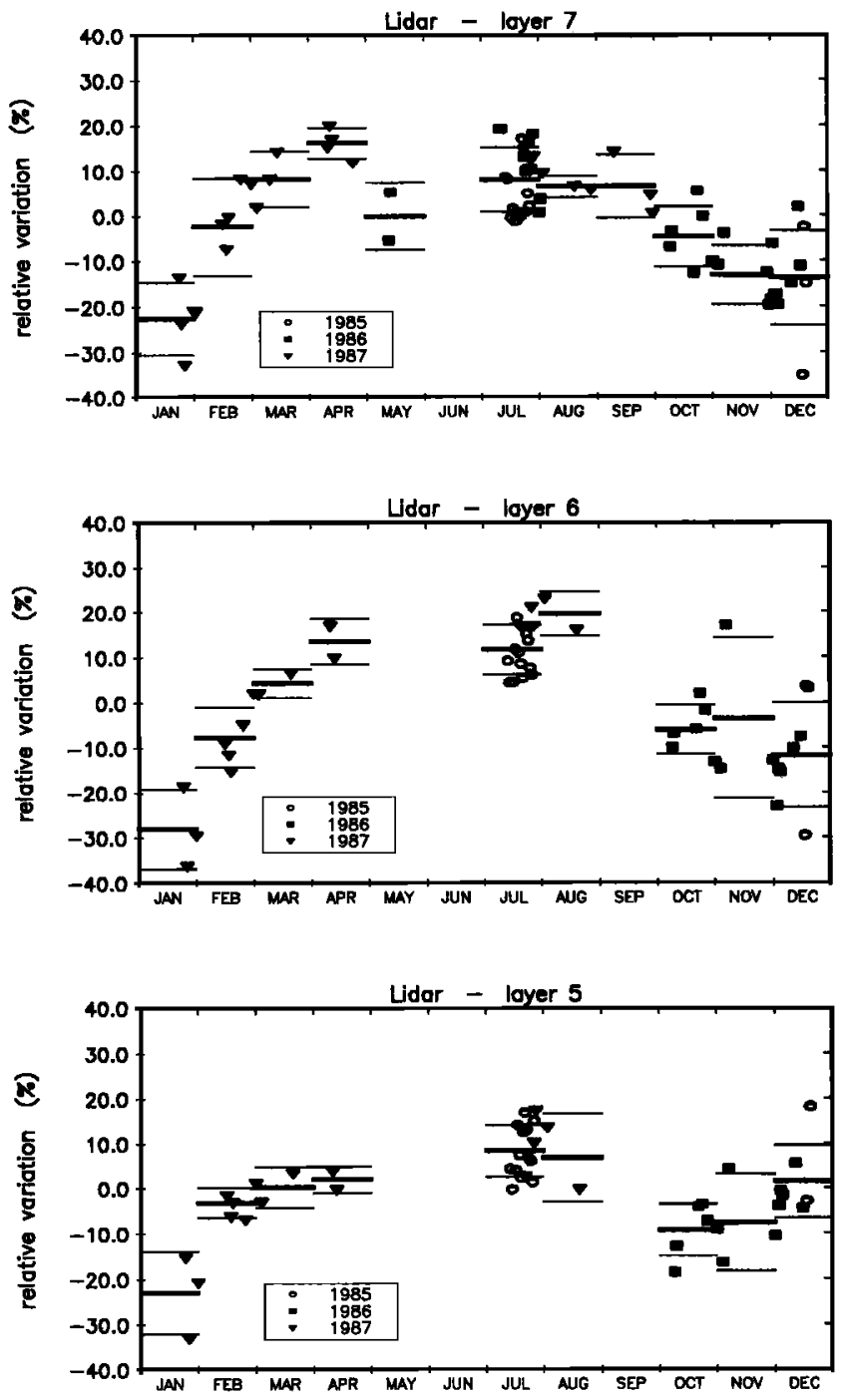

Fig. 1 : Seasonal variation of the ozone content as measured by lidar at the O.H.P. and averaged over various Umkehr layers (a) layer 5- 23-28 $\mathrm{km}$; b) layer 6-28-33 km; c) layer $733-38 \mathrm{~km}$ )

planetary wave activity is quite strong and drives the ozone behaviour in this altitude range. They should then not be considered as fully significative. In the above layer 6 (figure $1 \mathrm{~b}$ ) the amplitude of the seasonal variation is larger ( 30 8) with a summer maximum in the ozone concentration. The standard deviation of the measurements which can be attributed to a large extent to the natural variability is larger during winter, emphasizing again the importance of dynamical processes related to wave propagation. At higher altitudes (1ayer 7 - figure 1c), the peak-to-peak variation is again of the order of $35 \%$, whereas the shape of the variation appears different with a maximum extending through spring and summer. Here again the day-to-day variability is somewhat larger during the winter months.

The comparison with the Umkehr retrieved profiles show a rather good agreement with the lidar data as far as the general features of the seasonal variation are concerned. The figure 2 


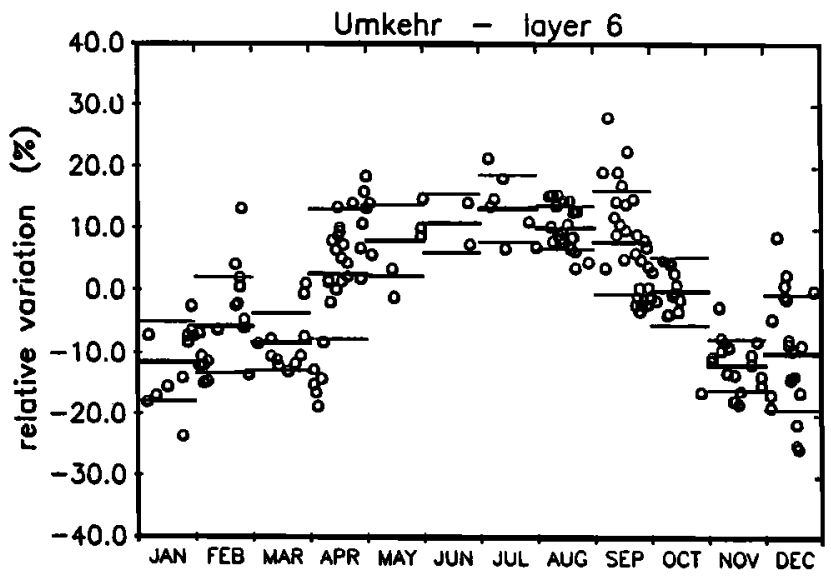

Fig. 2 : Seasonal variation of the ozone content in the Umkehr layer 6 as measured by the Dobson spectrophotometer at the O.H.P.

represents the seasonal variation for the Umkehr layer 6. The major difference lies in the amplitude of the observed variations which are generally 20 to 40 higher on the lidar data. This effect can most 1 ikely be attributed to the non-Independance of the various Umkehr layers for Dobson spectrophotometer measurements. Due to the different amplitudes of the ozone variations throughout the altitude range, this interdependance results in an avelaging effect which reduces the amplitude and modifies the phase of the altitude dependent ozone variations. This can be further assessed if one considers the direct lidar measurements at a given altitude ( $35 \mathrm{~km} \pm 1 \mathrm{~km}$, figure 3 ) obtained with a higher vertical resolution which show a significantly larger peak-to-peak amplitude ($508)$.

To allow a further comparison of the absolute values of the ozone concentration as retrieved by lidar and by the Umkehr technique at the OHP, all profiles colncident in time have been averaged to provide an accurate estimate of a possible bias. 25 profiles were compared as shown on figure 4 (Umkehr minus lidar refered to Umkehr values) showing a negative bias at lower altitudes (layers 5 and 6 ) shifting to a positive bias increasing up to 10 in the upper layers 7 and 8 .

To account for a possible effect of the seasonal varlation, comparisons have also been made averaging only summer-time measurements (figure 4) which shows however similar values of the bias. As measurements were taken in the years 1985-1986, one should not expect a large effect of aerosol interferences in the Umkehr measurments as the high stratospheric aerosol load following the E1 Chichon eruption (Mars-April 1982) had already decreased by one order of magnitude resulting in optical thicknesses below 0.015 as measured by lidar at the same site. This value is compatible with the observed bias in layers 5 and 6 (De Luisi, 1979) whereas it could not explain the positive bias observed in the upper layers and especially the large bias observed in layer 7. It should be mentionned however that a similar positive bias has been found between the SAGE I and the Umkehr

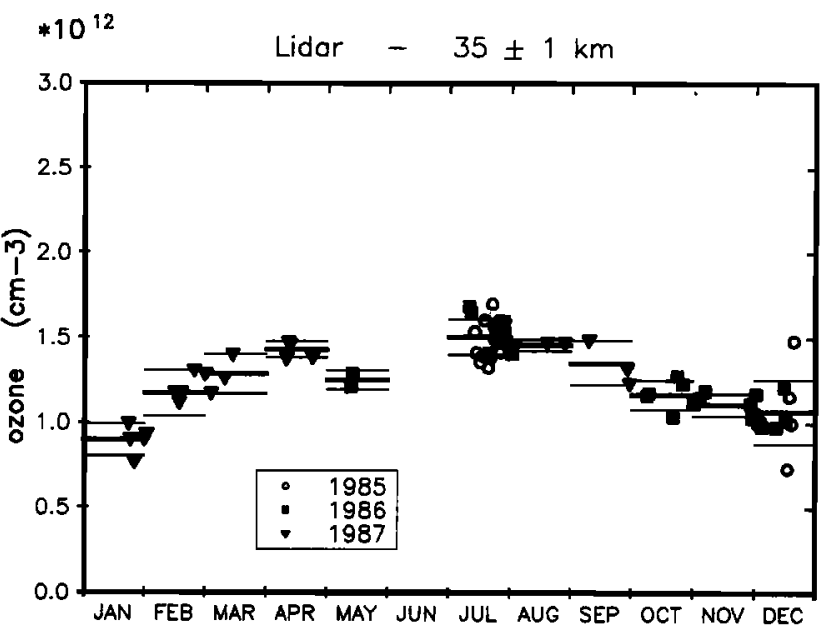

Fig. 3 : Seasonal variation of the ozone number density at $35 \pm 1 \mathrm{~km}$ as measured by lidar at the O.H.P.. The monthly averages are given by the thick lines and the standard deviations are indicated by the thin lines.

summertime measurements, based on 36 observations performed in 1979 and 1981 (Newchurch et al., 1987). Extension of the lidar data base to provide monthly averaged comparisons will bring further information on a potential seasonal variation of the bias allowing thus to distinguish between the various influencing factors related to data conversion such as temperature, pressure and geopotential height.

\section{Conclusion}

Operational lidar measurements performed at the Observatoire de Haute Provence (1985-1987) confirm the ability of such systems to provide a continuous survey of the ozone vertical distribution in the $25-45 \mathrm{~km}$ altitude range. Lidar observed seasonal variations of the ozone concentration give evidence for a transition between dynamically controled region at lower altitude and photochemical influence at upper level. If the same features are also observed on

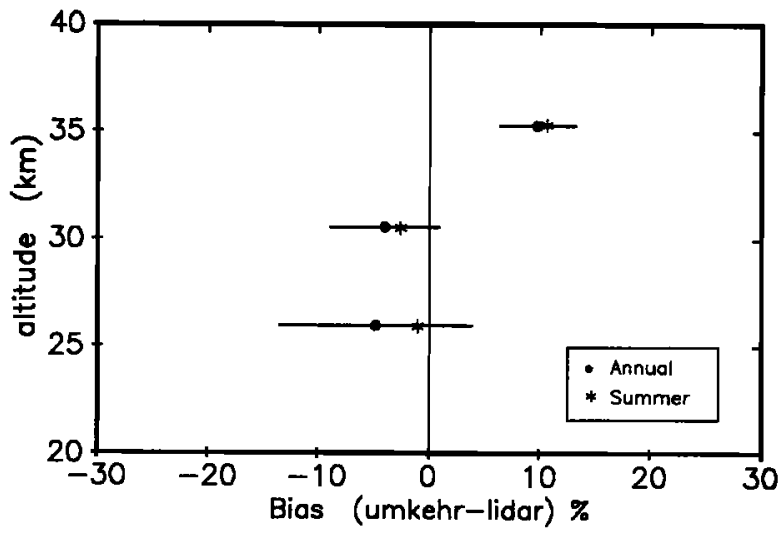

Fig. 4 : Relative bias between the Umkehr and lidar measured ozone vertical distribution at 0.H.P. The error bars indicate the $1 \sigma$ confidence intervals as calculated from the data base. 
Umkehr measurements, lidar observations show larger amplitudes in the retrieved variations related to the higher vertical resolution of the systen. In terms of absolue values, statistically significant comparison show a rather good agreement between lidar and Umkehr retrieved ozone values in layers 5 and 6 , although unexpected positive bias corresponding to larger Unkehr values are observed in layers 7 and 8 .

Continuation of the ozone lidar operation are planned to increase the data base. They are complemented by other lidar measurements of aerosol and temperature, automated Dobson observation of the total ozone content and vertical distribution by the Umkehr technique. Future addition of microwave measurements of chlorine monoxide distribution and UV-visible spectrometer measurements of ozone and nitrogen dioxide is also planned. The global system such implemented at the Observatoire de Haute Provence will thus constitute the basis of an established site of the future Network for Detection of Stratospheric Changes.

Acknowledgements. The Geophysical Station at the Observatoire de Haute Provence is operated with the financial support of the french Centre National de la Recherche Scientifique, Institut National des Sciences de l'Univers, Centre National d'Etudes Spatiales and Ministère de l'Environnement. The implementation of the ozone lidar has been supported by a grant from the Chemical Manufacturers Assiociation FPP Pannel. The authors wish to thank particularly Philippe Gildwarg for his contribution to the system operation and data acquisition, J.P. Schneider and $F$. Syda for their responsability in the overall maintenance of the station, and $P$. Marche, A Bekkadour and C. Da Canceicao for providing the Dobson data.

\section{References}

De Luisi J.J. (1979) : Umkehr vertical ozone profile errors caused by the presence of stratospheric aerosols. J, Geophys. Res, 84,766 .

Godin S., J. Pelon and G. Mégie (1986) :Liđar Stratospheric Measurements at the Observatoire de Haute Provence. 13th International Laser Radar Conference, NASA Conference Publication G2431, 215.

Godin S. (1987) : Etude expérimentale par télédétection laser et modélisation de la distribution verticale d'ozone dans la haute stratosphère. Thèse de Doctorat de l'Université Pierre et Marie Curie, Paris.

Godin S., G. Mégie, J. Pelon, A.J. Miller, R.M. Nagatani and A.J. Fleig (1988) :Comparison of the ozone vertical distribution obtained by lidar and by the SBUV instrument. Quadrennial Ozone Symposium, ed. R. Bojkov and P. Fabian, Götttingen (RFA).

Marché $P$., Meunier C., Barbe $A$. and Jouve $P$. (1983) : Total atmospheric ozone measured by ground-based high resolution infra-red spectra. Comparison with Dobson measurements. Planet. Space Sci., 39, 791.

Mégie G., J.Y. Allain, M.L. Chanin and J.E. Blamont (1977) : Vertical profile of stratospheric ozone $(18-28 \mathrm{~km})$ by 1 idar sounding from the ground. Nature, $270,329$.

Mégie G. and R.T. Menzles (1980) : Complementarity of $\mathrm{UV}$ and IR differential absorption lidar for global measurements of atmospheric species. Appl. Opt,, 19, 7,1173.

Mégie G., G. Ancellet and J. Pelon (1985): Lidar measurements of ozone vertical profiles. App1. Opt., 24, 21,3454-3463.

NASA (1986) : Network for the Detection of Stratospheric Changes. Report of the Workshop, Boulder, Colorado, March 5-7, 1986. Atmospheric Research Program, NASA Headquarters, Washington D.C. .

NASA (1988) : Present state of knowledge of the Upper Atmosphere 1988 : An Assessment Report. NASA Reference Publication 1208, OSSA, Washington D.C., August 1988.

Pelon J. and G. Mégie (1981) : Ozone monitoring in the troposphere and lower stratosphere : evaluation and operation of a ground based lidar station. J. Geophys. Res,, 87, C7, 4947-4956.

Pelon J. and G. Mégie (1982) :Ozone vertical distribution and total content using a ground based active remote sensing system. Nature, $299,137-139$.

Schotland R.M. (1964) : The determination of the vertical profile of atmospheric gases by means of a ground based optical radar. Proceedings of the 3rd Symposium on Remote Sensing of the Environment, Ann Arbor, U.S.A. .

S. Godin, G. Mégie, J. Pelon, Service d'Aéronomie du CNRS, Université Pierre et Marie Curie, Tour 15-14 5ème étage, 4 Place Jussieu, 75230 Paris Cedex 05.

(Received December 30, 1988; accepted January 24, 1989) 